World and the New through eastern Asia. No reference is made to recent research, which seems to point to its existence in Europe in early prehistoric times. The cults and ritual of myth are discussed in two articles, one by Prof. K. Th. Preuss on the significance of birth and death and their relation to initiation and other forms of ceremonial in which sex is an element, and the second by Prof. Gustav Hübener, who regards the position of the hero in early epics as based upon his power as an exorcist. Although this does not exhaust the list of contents, mention can be made here of one other paper only-Prof. Erich Haenisch's interesting suggestion that the vertical arrangement in Chinese writing is due to the form of the ancestral tablet. The papers are brief, running to two or three pages only, and the treatment summary and popular. As a counter to English comment on Germany's 'purge', it does not make a really impressive showing.

\section{Studies of the Rarer Elements}

IN his address as retiring president to the Chemical Society given on March 28 and entitled "Recent Researches on Certain of the Rarer Elements" (J. Chem. Soc., p. 554, April 1935), Prof. G. T. Morgan outlined some of the most important advances which have been made in recent years in the study of the rarer elements. The British Empire is endowed with mineral resources to an extent unsurpassed by those of any other nation. It is obviously the duty of British chemists to undertake the systematic investigation of the rarer elements of the Empire, for it is certain that results of inestimable value will be forthcoming. Prof. Morgan is him. self an outstanding leader in this kind of work and the results which he and his colleagues have accumulated form the main topic of the address. The extraction of germanium and gallium from Northumberland coal-ash has been started by Dr. G. R. Davies. Certain seams of Northumbrian coal give an ash containing up to 1 per cent of germanium and 0.05 per cent of gallium. The germanium is distilled out with acid as tetrachloride, whilst gallium trichloride remains in the still. A diagram of the apparatus is given. Rhenium has been extracted from Australian molybdenite by a lengthy process involving fractional volatilisation and ultimate separation with organic reagents such as 8-hydroxyquinoline and dipyridyl. The address concludes with some notes on the co-ordination compounds of ruthenium, amongst which is an ammine which dyes natural silk in red shades but is extremely difficult to isolate in a state of purity.

\section{A Central Statistical Institute}

DESPITE the immense increase in the amount of statistical material which has become available during recent years, investigators still lack the data for even approximate measurement of many of the most important economic forces. In an article in World Survey of May 1935 entitled "The Case for Economic Measurement", Mr. G. D. H. Cole pleads for the establishment of a Central Statistical Institute in
Great Britain which would undertake the regular and prompt compilation and issue of this type of information, including regular surveys of production, prices, wholesale and retail trade, population movements and the like: He also advocates the publication of an annual "Progress of Britain Report" like that issued by the Government of India. The annual "Statistical Abstracts of the United Kingdom", it is true, go back nearly to the middle of the nineteenth century, and though greatly improved since the early issues, they have by no means been expanded in proportion to the development of the official corpus of statistics taken as a whole, and anyone who wants to collect the bare essentials of the current statistics in Great Britain has to work through much seattered material in numerous official publications. Mr. Cole also states that the publications of the Stationery Office on the subject are often expensive; while in most towns it is impossible to find any place where even the most important public documents can be consulted, and for private students or even small institutions, the cost of buying the bare minimum of requisite reports is excessive.

\section{Prices of Biological Books in 1934}

Tнस analysis of the cost of biological books in 1934, by John R. Miner (Quart. Rev. Biol., Dec. 1934 , p. 496), illustrates the significance of the devaluation of the dollar in affecting relative prices of American and foreign books. The estimates of cost are worked out in cents per page, the price of a foreign book being converted at the current rate of exchange, and the total number of pages upon which the calculations are based is 123,876 . The only country in which prices have fallen is U.S.A. where (at 0.93 cents a page) there has been a drop of almost 9 per cent compared with 1933 prices. British Government publications have dropped from $1 \cdot 39$ to 0.89 cents a page and are now the cheapest of the lot apart from U.S. Government publications, which are issued at the amazingly low price of 0.18 cents a page; but the British Government sample was too small to be reliable. British books, on the other hand, have risen in terms of dollars by 45.5 per cent, French by 35 and German by 32 . As to relative prices, British books now slightly exceed in price American books $(0.96$ against 0.93$)$, France stands at 1.00 and Germany at 1.89 cents a page. As was noted in the report for 1933, the high prices of German scientific books and periodicals have proved a hardship to libraries and individual workers, and although as the result of a conference with German publishers some reductions in the prices of scientific periodicals have been made, evidently these reductions do not extend to scientific books.

\section{Books on Horticulture}

Messrs. Wheldon and Wesley, Lidd, of 2, 3 and 4 Arthur Street, New Oxford Street, London, W.C.2, have rendered a valuable service to gardeners by compiling a "Comprehensive List of Books on all Branches of Modern Horticulture, and a Selection of the Early Literature" (New Series, No. 39, 1935). 